\title{
Author Index Volume 21 (2012)
}

The issue number is given in front of the pagination

Abdolalizadeh, J., M. Nouri, J.M. Zolbanin, B. Baradaran, A. Barzegari and Y. Omidi, Downstream characterization of anti-TNF- $\alpha$ single chain variable fragment antibodies $(1,2) 41-48$

Abdolalizadeh, J., see Sepehr,K.S. (3,4) 57-64

Aghebati, L., see Sepehr,K.S. (3,4) 57-64

Banerjee, S., see Li, L. (3,4) 65-73

Baradaran, B., see Abdolalizadeh, J. (1,2) 41-48

Baradaran, B., see Sepehr,K.S. (3,4) 57-64

Barzegari, A., see Abdolalizadeh, J. (1,2) 41-48

Delcommenne, M. and H.-G. Klingemann, Detection and characterization of syndecan-1-associated heparan sulfate 6- $O$-sulfated motifs overexpressed in multiple myeloma cells using single chain antibody variable fragments $(1,2)$ 29-40

Dreja, H., see Tang, J. (1,2) 1-11

Dübel, S., see Wezler, X. (1,2) 13-28

Gorny, M.K., see Li, L. (3,4) 65-73

He, M., see Tang, J. (1,2) 1-11

Helmsing, S., see Wezler, X. (1,2) 13-28

Hust, M., see Wezler, X. (1,2) 13-28

Jeffs, S.A., see Tang, J. (1,2) 1-11

Kang, A.S., see Tang, J. (1,2) 1-11

Klingemann, H.-G., see Delcommenne, M. $(1,2) 29-40$ Kouchakzadeh, H., S.A. Shojaosadati, J. Mohammadnejad, M. Paknejad and M.J. Rasaee, Attachment of an anti-MUC1 monoclonal antibody to 5-FU loaded BSA nanoparticles for active targeting of breast cancer cells $(3,4) 49-56$

Li, L., X.-H. Wang, S. Banerjee, B. Volsky, C. Williams, M.A. Moody, S. Zolla-Pazner and M.K. Gorny, Clonal analysis of human anti-V3 mono- clonal antibodies selected by a V3 tetramer $(3,4)$ $65-73$

Majidi, J., see Sepehr,K.S. (3,4) 57-64

Markiv, A., see Tang, J. (1,2) 1-11

McKnight, Á., see Tang, J. (1,2) 1-11

Mohammadnejad, J., see Kouchakzadeh, H. $(3,4) 49-$ 56

Moody, M.A., see Li, L. $(3,4) 65-73$

Nouri, M., see Abdolalizadeh, J. (1,2) 41-48

Omidi, Y., see Abdolalizadeh, J. (1,2) 41-48

Paknejad, M., see Kouchakzadeh, H. (3,4) 49-56

Rasaee, M.J., see Kouchakzadeh, H. (3,4) 49-56

Schirrmann, T., see Wezler, X. (1,2) 13-28

Sepehr,K.S., B. Baradaran, J. Majidi, J. Abdolalizadeh, L. Aghebati and F.Z. Shahneh, Development and characterization of monoclonal antibodies against human CD20 in Balb/c mice $(3,4)$ 57-64

Shahneh, F.Z., see Sepehr,K.S. (3,4) 57-64

Shojaosadati, S.A., see Kouchakzadeh, H. $(3,4)$ 49-56

Tang, J., L. Wang, A. Markiv, S.A. Jeffs, H. Dreja, Á. McKnight, M. He and A.S. Kang, Accessing of recombinant human monoclonal antibodies from patient libraries by eukaryotic ribosome display $(1,2) 1-11$

Volsky, B., see Li, L. $(3,4) 65-73$

Wang, L., see Tang, J. (1,2) 1-11

Wang, X.-H., see Li, L. (3,4) 65-73

Wezler, X., M. Hust, S. Helmsing, T. Schirrmann and S. Dübel, Human antibodies targeting CD30 ${ }^{+}$lymphomas $(1,2)$ 13-28 
Williams, C., see Li, L. (3,4) 65-73

Zolla-Pazner, S., see Li, L. (3,4) 65-73

Zolbanin, J.M., see Abdolalizadeh, J. (1,2) 41-48 